The International Economy, Vol. 21, 2018

\title{
Internal Remittances, Vocational Training Costs and Rural-Urban Migration in Developing Countries*
}

\author{
Dianshuang Wang ${ }^{\dagger}$ \\ Graduate School of Economics, Nagoya University
}

\begin{abstract}
The paper develops a three-sector general equilibrium model to examine the consequences of an increase in vocational training costs on internal remittances in a small open dual economy. Using indirect utility functions, the paper endogenizes the internal remittances. The theoretical analysis shows that an increase in vocational training cost of the manufacturing sector decreases internal remittances and the proportion of remittances in migrants' income. In addition, an increase in per capita training cost also contributes to expanding the informal sector and contracting the agricultural sector.
\end{abstract}

JEL: R23; I24; J6

Key words: Internal remittances; vocational training cost; rural-urban migration

\section{Introduction}

Internal migration in general and rural-urban migration in particular are often viewed as the labor market adjustment to the inter-sectoral shift in importance from agriculture to manufacturing and services. This phenomenon has historically been a significant factor for economic structural changes in developed countries, while many developing countries are experiencing the same process currently, especially in countries with a large population. Take China and India for example. According to China's recent national statistics, rural migrants have increased from 229.78 million in 2009 to 281.71 million in 2016. ${ }^{1)}$ From the Census of India 2011, rural migrants are nearly 400 million, comprising a third of India's population.

One of the most conspicuous effects of internal migration is the huge flow of remittances within the country. ${ }^{2)}$ There are no accurate statistics on the total amount of internal remit-

Received 9 August 2017, Accepted 26 January 2018, Released online in J-STAGE as advanced publication 28 February 2018.

* I would like to express my deep appreciation to Prof. Yanase Akihiko and Prof. Yanagihara Mitsuyoshi for helpful comments at the earlier version of this paper and anonymous reviewers for insightful comments on this paper. Needless to say, possible remaining errors are solely the responsibility of the author. The author also gratefully acknowledges financial support from China Scholarship Council.

$\dagger$ Address for correspondence: Graduate School of Economics, Nagoya University, Furo-cho, Chikusaku, Nagoya, 464-8601, Japan. Email: wang.dianshuang@d.mbox.nagoya-u.ac.jp.

1) National Bureau of Statistics of PRC, National Monitoring Survey Report of Rural-Urban Migrant Workers from 2009 to 2016

2) Different with internal remittances, external remittances or international remittances has captured lots of 
tances, but a rough estimate can be made. Based on national statistics, the estimation for China shows that the internal remittances are near one trillion RMB (around 160 billion US dollars) in 2013 (Li and Wang, 2015). A survey conducted by National Sample Survey Organization shows around $58 \%$ of the domestic migrants send money home with an average remittance size of INR 13,000 (about 200 US dollars) in a year in India in 2008. ${ }^{3)}$ Moreover, internal remittances could transfer in various forms and actual internal remittances would probably be much larger than the estimated figure. For example, the internal remittances market in India is dominated by the unorganized or informal channels of money transfer in 2008, which together accounted for $70.0 \%$ of the remittances. ${ }^{4)}$ The remittances sent by migrants play a significant role in rural development in developing countries. Internal remittances, comprising $20 \%$ to $50 \%$ of total family income in the receiving household, are crucial to paying for household expenses in China (Cheng and $\mathrm{Xu}, 2005$ ). In India, internal remittances financed over $30 \%$ of household consumption expenditure and $80 \%$ went to rural households (Tumbe, 2011). In addition, remittances are safety funds for relatively poor areas, as they are freer from political barriers and controls than either products or other capital flows in developing countries.

Migrants' income, which is significantly affected by their human capital level, determines the capacity of remittances. Due to the backward education system in rural regions, migrants' human capital level is much lower than their counterparts in the urban. Thus, the poor education migrants have received and the low skills they possess have seriously hurdled their way into the urban manufacturing sector. Generally, offering basic education in regular schools before employment and developing skill through vocational training are main approaches for human capital accumulation. Thus, after transferring to an urban region, vocational training is the main approach to increase their human capital through "learning by doing." On the one hand, through vocational training, migrants could grasp industry-based and professional competencies to meet skill requirements in a short period, which bring better employment opportunities for them. On the other hand, industries could hire technical workers to handle new equipment. Therefore, government and firms make endeavors to overcome the shortcomings of the education system by offering vocational training. ${ }^{5)}$ Vocational training also incurs costs. In developed countries, these are borne jointly by firms, individuals and the state. While

attention to development economists. The latest figure on external remittances is above US \$441 billion, nearly three times the amount of official development assistance (World Bank, 2016).

3) See http://catalog.ihsn.org/index.php/catalog/1907

4) See https://www.kenresearch.com/banking-financial-services-and-insurance/financial-services/indiadomestic-remittance-market-research-report/474-93.html

5) With the transformation and upgrading of China's industrial structure, the Chinese government released "Decision on Accelerating the Development of Modern Vocational Education" to promote the development of vocational education. According to the Decision, it is estimated that "by 2020, there will be 23.5 million students receiving secondary vocational education, 14.8 million students receiving vocational education at college level, and the number of students receiving vocational education at university level will also reach a certain scale. The number of practitioners receiving continuing education will hit 350 million." Government of Pakistan published The Vision 2025, which is a long-term strategic road map for the country's sustainable socioeconomic development, has six core objectives, all of which are closely linked to vocational training. Government of India set up the National Mission for Skills to create a larger skilled workforce and announced a centrally-sponsored program to upgrade all industrial training institutes (ITIs). 
in developing countries, a larger proportion is born by the state and firms to stimulate the participation of eligible workers ${ }^{6}$. Under the background of industries upgrading and economic structural adjustment, it is obvious that the per capita cost of vocational training increases even though objective calculation of the costs of vocational training faces considerable difficulties. Consequently, firms with capable of workforce and modern equipment employ less workforce, particularly in labor-intensive sectors where capital substitutes for less skilled labor. At the aggregate level, this change also induces a changing demand for labor, demanding higherquality labor rather than a higher number of employees.

In studies of the vocational training cost under the framework of internal migration, Djajic (1985) considered all individuals are born with identical ability and some choose to acquire skills which require finances while others remain unskilled. He examined the link between the minimum wage and unemployment in the context of an open-economy model. Samanta (2003) extended the Harris and Todaro model with the assumption that urban firms provide training to the workers and analyzed the economic effects of the training of urban sector employees. Li and Zhou (2013b) considered the situation where rural labor could enter into the producer services sector only by means of vocational training, and they investigated the environmental impacts of a change in training cost. However, the existing literature on training cost fails to consider the issue of internal remittances, and thus fails to investigate the effect of a change in training cost on internal remittances.

Massive remittances have motivated great interest in economists; however, most of the attention was paid to international remittances; internal remittances have received attention only recently and most papers on internal remittances concentrate on two aspects empirically: their determinants (Niimi et al, 2009; Brauw and Mueller, 2013) and effects (Adams, 2010; Mueller and Shariff, 2011; Adams, 2013). Nevertheless, theoretical research has been sparse in this field. Li and Zhou (2013a) investigated the impact exerted by a change in the remittances rate of the unskilled migrants on the wage inequality in the labor host region and found that an increase in their remittances rate decrease wage inequality in the labor host region. Li and Zhou (2015) considered a model that incorporates natural environment and remittances: urban manufacturing sector absorbs rural-urban migrants and generates pollution, and agricultural production depends on environmental factors. Under the model, they analyzed the short-term and long-term impacts of an increase in remittances of migrants on the environment with the model and arrived that the increase of migrant remittance can improve the environment in the short term but worsen the environment in the long run. Li and Wang (2015) considered the economic impact of migrants' remittances on the labor host regions from the short- and long-term perspectives and concluded that an increase in remittances will reduce the output of the informal sector and decrease urban residents' welfare in the short term, while it has opposite effects in the long term. Unfortunately, the existing literature treated internal remittances as an exogenous variable and analyzed their effects on economy and environment. Nevertheless, different from international remittances, which are largely determined without one economy, the internal remittances are determined within one economy and influenced by many factors of migrants. Training cost affects the employment of

6) In developing countries, the expensive training fee is beyond most workers' reach. In addition, a majority of workers hold that they should bear a fraction of the training fee. 
rural workers and their income, which further exerts an impact on internal remittances. However, the existing literature on internal remittances neglects to consider the issue of training cost in manufacturing, and thus fails to investigate the effect of a change in training cost on internal remittances.

In order to fill the current research gap, this paper tries to integrate vocational training cost and internal remittances into a unified framework of labor migration. The economic intuition of this paper can be briefly described as follows: an increase in per capita cost of vocational training in manufacturing sector will reduce the amount of employment, which further changes the employment of informal and agricultural sector. On the one hand, migrants' income and urban consumption also change consequently, which affects the capacity of internal remittances. On the other hand, rural income varies as a result of a change of employment in the agricultural sector. Rural income affects its utility, which further changes the remittances under the assumption that migrants remit for purely altruistic reasons. Combining the above two aspects, we can arrive at how vocational training cost exerts impacts on internal remittances in developing countries.

Thus, this paper establishes a three-sector general equilibrium model and tries to analyze how a change of per capita vocational training cost affects internal remittances in developing countries. In the model, we find that an increase of per capita cost of vocational training will reduce the internal remittances and the proportion of remittances in migrants' income. In addition, an increase in per capita training cost also contributes to expanding the informal sector and contracting the agricultural sector. The rest of this paper is organized as follows: The model is provided in Section 2. Section 3 examines the impacts of a change of per capita training cost on remittances. Section 4 makes some conclusions.

\section{Theoretical model}

The article considers a small, open, developing economy with three sectors: an urban formal manufacturing sector (sector 1), an urban informal sector (sector 2) and a rural agricultural sector (sector 3). The urban informal sector refers to the urban small-service sector. Products from the informal sector cannot transport and consumption is confined to local residents. Since such service products are rare in a rural area, the paper assumes the informal sector provides domestic services to urban residents only ${ }^{7}$. The manufacturing sector and the agricultural sector produce traded goods, while the informal sector produces non-traded goods. Prefect competition is assumed to prevail in the economy. The manufacturing sector and the informal sector only use labor to produce goods, while the agricultural sector relies on labor and land. The wage of the urban manufacturer is inelastic, but wages of agriculture and informal sector are elastic.

In developing countries, the urban labor market is segmented between migrants and nonmigrants, and there is little competition between them, and non-migrants have a huge advantage in the market (Knight et al, 1999; Meng and Zhang, 2001). To simplify the analysis, the

7) The informal sector is largely characterized by several qualities: easy entry, a lack of stable employeremployee relationships, a small scale of operations. Included in this sector are newsstand owners, street vendors, shoeshine boys, and so forth. See the theoretical studies of informal by Gupta (1997), Kar and Marjit (2001). etc. 


\section{Wang}

paper assumes that urban labor holds employment in the manufacturing sector constantly and only rural labor experiences the change of employment in different sectors ${ }^{8)}$. Since rural migrants' human capital level lags behind urban counterparts, the manufacturing sector would invest in the employees' skills to meet the requirements. We assume the training cost of each labor is $h$ in the manufacturing, and firms in manufacturing bear the cost of vocational training alone. $\left.{ }^{9}\right) q(h)$ expresses the efficiency of each migrant after vocational training, that is, the minimum per capita human capital level needed by the manufacturing sector. $q(h)$ satisfies the conditions $q(0)=1, q^{\prime}(h)>0$ and $q^{\prime \prime}(h)<0$. Production functions for each sector are:

$$
\begin{aligned}
& X_{1}=F^{1}\left(\bar{L}_{1}, q(h) L_{1}\right) \\
& X_{2}=F^{2}\left(\bar{L}_{2}+L_{2}\right) \\
& X_{3}=k(\beta) F^{3}\left(L_{3}, T\right)
\end{aligned}
$$

where $F^{i}(i=1,2,3)$ means the production function of the three sectors, all are strictly quasiconcave, linearly homogeneous function. Note, urban labor and transferred migrants are not perfect substitution in the manufacturing sector. $\bar{L}_{i}(i=1,2)$ is employment of urban citizens in sector $i . \quad L_{i}(i=1,2,3)$ is the rural labor employed in sector $i$. $T$ is land employed in the agricultural sector. $\beta$ is the remittances sent by migrants. Assume that remittances have a positive effect on agricultural production, use $k$ to denote the impact. And $k(\beta)$ has the property that: $k(0)=1, k^{\prime}(\beta)>0, k^{\prime \prime}(\beta)=0$.

Profit maximization of three sector yields:

$$
\begin{aligned}
& q(h) p_{1} F_{L}^{1}\left(\bar{L}_{1}, q(h) L_{1}\right)=h+\bar{w} \\
& p_{2} F_{L}^{2}\left(\bar{L}_{2}+L_{2}\right)=w_{2} \\
& k(\beta) F_{L}^{3}\left(L_{3}, T\right)=w_{3}
\end{aligned}
$$

where $F_{L}^{i}=\partial F^{i} / \partial L_{i}>0(i=1,2,3)$ are the marginal products of labor in respective sectors. $\bar{w}$ is the wage level of the manufacturing sector, while $w_{2}$ and $w_{3}$ refer to the wage levels of informal and agricultural sectors. In the model, the price of agricultural goods is assumed as 1 , and $p_{i}(i=1,2)$ is the price of the goods in sector $i$ relative to that of agricultural goods.

Rural labor market-clearing condition could be shown as follows:

$$
L_{1}+L_{2}+L_{3}=L_{R}
$$

8) Note that urban labors in the manufacturing and informal sector are different and they hold their employment due to their priority in the labor market.

9) In general, firms and the government mainly bear the training cost in developing countries. Government pays the cost by tax revenue. Here, to simply the analysis, we assume firms offer necessary funds for the training alone. 
Internal Remittances, Vocational Training Costs and Rural-Urban Migration in Developing Countries

where $L_{R}$ is rural labor endowment. The rural labor allocation mechanism in sectors yields:

$$
w_{3}=\frac{L_{1}}{L_{1}+L_{2}} \bar{w}+\frac{L_{2}}{L_{1}+L_{2}} w_{2}
$$

where $L_{1} /\left(L_{1}+L_{2}\right)$ and $L_{2} /\left(L_{1}+L_{2}\right)$ are the probability of migrants to be employed by the manufacturing sector and informal sector, respectively.

The following considers the consumption. There are three types of labor: urban labor, rural migrants and rural labor. The representative labor who is an urban citizen has utility function $U^{U}\left(D_{1}^{U}, D_{2}^{U}, D_{3}^{U}\right)=\alpha_{1}^{U} \ln D_{1}^{U}+\alpha_{2}^{U} \ln D_{2}^{U}+\alpha_{3}^{U} \ln D_{3}^{U}$, where $D_{1}^{U}, D_{2}^{U}$ and $D_{3}^{U}$ denote the consumption of goods of the manufacturing sector, informal sector and agricultural sector, respectively; $\alpha_{1}^{U}, \alpha_{2}^{U}$ and $\alpha_{3}^{U}$ are all positive parameters, and $\alpha_{1}^{U}+\alpha_{2}^{U}+\alpha_{3}^{U}=1$. Income of urban labor $y_{U}$ is expressed by $y_{U} \equiv p_{1} X_{1}+p_{2} X_{2}-L_{1}(h+\bar{w})-w_{2} L_{2}$, which means income deducts the training cost and migrants' income ${ }^{10)}$. By solving utility maximization problem, subject to the budget constraint: $p_{1} D_{1}^{U}+p_{2} D_{2}^{U}+D_{3}^{U}=y_{U}$, we have indirect utility $V^{U}\left(p_{1}, p_{2}, 1, y_{U}\right)=\sum_{i=1}^{3} \alpha_{i}^{U} \ln \alpha_{i}^{U}+\ln y_{U}-\alpha_{1}^{U} \ln p_{1}-\alpha_{2}^{U} \ln p_{2}$. The representative labor who is a rural migrant has utility function $U^{T}\left(D_{1}^{T}, D_{2}^{T}, D_{3}^{T}\right)=\alpha_{1}^{T} \ln D_{1}^{T}+\alpha_{2}^{T} \ln D_{2}^{T}+\alpha_{3}^{T} \ln D_{3}^{T}$, where $D_{1}^{T}, D_{2}^{T}$ and $D_{3}^{T}$ denote the consumption of goods of the manufacturing sector, informal sector and agricultural sector, respectively; $\alpha_{1}^{T}, \alpha_{2}^{T}$ and $\alpha_{3}^{T}$ are all positive parameters, and $\alpha_{1}^{T}+\alpha_{2}^{T}+\alpha_{3}^{T}=1$. Disposable income of migrants $y_{T}$ is expressed by $y_{T} \equiv \bar{w} L_{1}+w_{2} L_{2}-\beta$, which means income subtracts the internal remittances. From budget constraint $p_{1} D_{1}^{T}+$ $p_{2} D_{2}^{T}+D_{3}^{T}=y_{T}$, we can arrive the corresponding indirect utility of migrants is $V^{T}\left(p_{1}, p_{2}, 1, y_{T}\right)=\sum_{i=1}^{3} \alpha_{i}^{T} \ln \alpha_{i}^{T}+\ln y_{T}-\alpha_{1}^{T} \ln p_{1}-\alpha_{2}^{T} \ln p_{2}$. The representative labor who is a rural labor has utility function $U^{A}\left(D_{1}^{A}, D_{3}^{A}\right)=\alpha_{1}^{A} \ln D_{1}^{A}+\alpha_{3}^{A} \ln D_{3}^{A}$, where $D_{1}^{A}$ and $D_{3}^{A}$ denote the consumption of goods of the manufacturing sector and agricultural sector. $\alpha_{1}^{A}$ and $\alpha_{3}^{A}$ are positive parameters, and $\alpha_{1}^{A}+\alpha_{3}^{A}=1$. Disposable income of rural labor is $y_{A} \equiv k F^{3}$ and budget constraint is $p_{1} D_{1}^{A}+D_{3}^{A}=y_{A}$. The indirect utility is $V^{A}\left(p_{1}, 1, y_{A}\right)=\alpha_{1}^{A} \ln \alpha_{1}^{A}+\alpha_{3}^{A} \ln \alpha_{3}^{A}+$ $\ln y_{A}-\alpha_{1}^{A} \ln p_{1}$.

As to the consumption of informal goods, urban labor and rural migrants spend $\alpha_{2}^{U}$ and $\alpha_{2}^{T}$ parts of disposable income on consumption of informal sector goods, respectively. Informal goods market-clearing condition can be demonstrated by:

$$
p_{2} X_{2}=D_{2}^{U}+D_{2}^{T}=\alpha_{2}^{U} y_{U}+\alpha_{2}^{T} y_{T}
$$

10) The revenue of urban labor is $y_{U} \equiv \bar{L}_{1} \bar{w}+w_{2} \bar{L}_{2}$. Using production function of manufacturing and informal sector, $p_{1} X_{1}=\bar{L}_{1} \bar{w}+(h+\bar{w}) L_{1}$ and $p_{2} X_{2}=w_{2} \bar{L}_{2}+w_{2} L_{2}$. Thus,we can find that $y_{U} \equiv p_{1} X_{1}+p_{2} X_{2}$ $-L_{1}(h+\bar{w})-w_{2} L_{2}$. 
Remittances affect labor's income and utility, therefore, the flow of remittances changes the utility of migrants and rural labors. The paper assumes that migrants remit for purely altruistic reasons in order to increase the utility of rural household by providing additional assistance. Consequently, the welfare of migrants consists of two parts: their own utility and their rural household's utility. The weight of own utility is $\theta(0<\theta<1)$, while the weight of rural household is $1-\theta$. Thus, the welfare of migrants $V^{T R}$ is the weighted average of two items: $V^{T R}=\theta V^{T}+(1-\theta) V^{A}$. Migrants choose an amount of remittances to maximize their welfare and derives,

$$
\frac{\theta}{L_{1} \bar{w}+L_{2} w_{2}-\beta}=\frac{(1-\theta) k^{\prime}}{k}
$$

The theoretical model thus consists of seven equations: (1)-(7). Endogenous variables are determined: $L_{1}, L_{2}, L_{3}, w_{2}, w_{3}, p_{2}$ and $\beta$.

\section{Comparative statics}

This section focuses on the economic effects of an increase in per capita vocational training cost on internal remittances based on the established model. Total differentiation of equations (1) to (7), and reorganize these equations into the following matrix notation ${ }^{11}$,

$$
\left(\begin{array}{cccc}
-k F_{L L}^{3} & 0 & -1 & k^{\prime} F_{L}^{3} \\
w_{3}-w_{2} & -L_{2} & L_{1}+L_{2} & 0 \\
\left(1-\alpha_{2}^{T}\right) w_{2} & \Omega_{0} & 0 & \alpha_{2}^{T} \\
(1-\theta) w_{2} & (1-\theta) L_{2} & 0 & -1
\end{array}\right)\left(\begin{array}{c}
d L_{2} \\
d w_{2} \\
d w_{3} \\
d \beta
\end{array}\right)=\left(\begin{array}{c}
\Omega_{2} k F_{L L}^{3} \\
\Omega_{2}\left(\bar{w}-w_{3}\right) \\
\Omega_{1} \\
-(1-\theta) \bar{w} \Omega_{2}
\end{array}\right) d h
$$

where $F_{L L}^{3}=\partial^{2} F^{3} / \partial L_{3}^{2}<0, \Omega_{0}=\left(1-\alpha_{2}^{U}\right) \bar{L}_{2}+\left(1-\alpha_{2}^{T}\right) L_{2}>0, \Omega_{1}=\alpha_{2}^{T} \bar{w} \Omega_{2}+\alpha_{2}^{U} L_{1}\left(p_{1} q^{\prime} F_{L}^{1}-1\right)$, and $\Omega_{2}=\left[1-p_{1} q^{\prime}\left(F_{L}^{1}+q F_{L L}^{1} L_{1}\right)\right] / q^{2} p_{1} F_{L L}^{1}$. Before we make the analysis, we need to determine the sign of $\Omega_{1}$ and $\Omega_{2}$, which are related with the training cost elasticity of $q$. Denote $\varepsilon_{h}=h q^{\prime} / q$ as training cost elasticity of $q$.

Assumption: $\varepsilon_{h}<h /(h+\bar{w})$ holds.

From the assumption, we have $\Omega_{1}<0$ and $\Omega_{2}<0$. The determinant of the coefficient matrix of the equation(8) is denoted as $\Delta$,

$$
\Delta=\bar{L}_{2}\left(1-\alpha_{2}^{U}\right)\left\{w_{3}-w_{2}+\left(L_{1}+L_{2}\right)\left[k^{\prime} F_{L}^{3} w_{2}(1-\theta)-k F_{L L}^{3}\right]\right\}
$$

11) The model can be decomposed. Totally differentiate equation(1), we can get the relationship between $h$ and $L_{1}$; from equation (2), we get the relationship between $p_{2}$ and $w_{2}$. Since $L_{1}$ is determined in equation (1), from equation (4), we can get the relationship between $L_{2}$ and $L_{3}$. Put three results of total differentiation in equation (1), (2) and (4) into the other four differentiation results, we can obtain equation (8). 
Internal Remittances, Vocational Training Costs and Rural-Urban Migration in Developing Countries

$$
+L_{2}\left(1-\alpha_{2}^{T} \theta\right)\left[w_{3}-k F_{L L}^{3}\left(L_{1}+L_{2}\right)\right]>0
$$

Next, we consider an increase in the per capita training cost on employment of rural labor among three sectors. From equation (1), we obtain that an increase in the per capita training cost will reduce the employment of migrants in the manufacturing sector. However, the distribution of the reduced workforce between informal and agricultural sector is unclear. We use Lemma 1 to describe the impacts of an increase in per capita training cost on employment of rural labor in the informal and agricultural sector.

Lemma 1 An increase in per capita training cost reduces agricultural employment and increases employment of migrants in the informal sector if $\frac{\bar{w} L_{1}+w_{2} L_{2}}{\beta}(1-\theta)>\frac{1}{\varepsilon_{\beta}}$, where $\varepsilon_{\beta}=k^{\prime} \beta / k$ denotes remittances elasticity of agriculture production.

\section{Proof}

From equation (1) and (5), we obtain $\frac{d L_{1}}{d h}+\frac{d L_{2}}{d h}=-\frac{d L_{3}}{d h}$ and $\frac{d L_{1}}{d h}=\Omega_{2}$. Using Cramer's rule in equation (8),

$$
\frac{d L_{2}}{d h}=\left\{\begin{array}{l}
\Omega_{2}\left[\left(1-\alpha_{2}^{U}\right) \bar{L}_{2}+L_{2}\left(1-\alpha_{2}^{T} \theta\right)\right]\left\{\bar{w}-w_{3}+\left(L_{1}+L_{2}\right)\left[k F_{L L}^{3}-(1-\theta) \bar{w} k^{\prime} F_{L}^{3}\right]\right\} \\
-L_{2}\left[(1-\theta) k^{\prime} F_{L}^{3}\left(L_{1}+L_{2}\right)-1\right]\left[\theta \bar{w} \Omega_{2}+\alpha_{2}^{U} L_{1}\left(p_{1} q^{\prime} F_{L}^{1}-1\right)\right]
\end{array}\right\} / \Delta
$$

Thus, we have

$$
\frac{d L_{3}}{d h}=\left[(1-\theta) k^{\prime} F_{L}^{3}\left(L_{1}+L_{2}\right)-1\right]\left[\left(\bar{w}-w_{2}\right) \Omega_{2} \Omega_{0}+w_{2} L_{2} \Omega_{2}-\alpha_{2}^{U}\left(L_{1}+\bar{L}_{1}\right) L_{2}\right] / \Delta
$$

If $\frac{\bar{w} L_{1}+w_{2} L_{2}}{\beta}(1-\theta)>\frac{1}{\varepsilon_{\beta}}$, we have $(1-\theta) k^{\prime} F_{L}^{3}\left(L_{1}+L_{2}\right)>1$ and further we get $\frac{d L_{2}}{d h}>0$ and $\frac{d L_{3}}{d h}<0$.

The condition in the Lemma $1 \frac{\bar{w} L_{1}+w_{2} L_{2}}{\beta}(1-\theta)>\frac{1}{\varepsilon_{\beta}}$ is made from the mathematical point of view, which may satisfy the real-world situation. In developing countries with the backward agricultural sector, agriculture is a lack of funds and a marginal increase in funds promotes agricultural production in a relatively large magnitude, thus the elasticity is likely greater than 1 and the right side of the inequality is likely lower than 1 . To the left side of inequality, migrants send parts of their income back and $\left(\bar{w} L_{1}+w_{2} L_{2}\right) / \beta>1$; since migrants have much connection between rural household, $1-\theta$ may much larger than $0 .{ }^{12}$ Therefore,

12) Since rural-urban migrants are mostly employed in dirty, dangerous and poorly paid occupations, most of them leave their family members, especially children, in rural areas. From the National Monitoring Survey Report of Rural-Urban Migrant Workers in 2015, only $21 \%$ of the rural-urban migration was family migration. In such situations, migrants spent on consumption prudently and remitted sizable percentages 


\section{Wang}

the left side of inequality may be larger than 1. From the discussion, it is reasonable to hold that the condition has wide representation in the real-world situation.

Next, we consider an increase in the per capita training cost on other economic variables. We show the result by solving equation (8),

$$
\begin{aligned}
& \frac{d w_{2}}{d h}=\left\{\begin{array}{l}
{\left[w_{3}-w_{2}-k F_{L L}^{3}\left(L_{1}+L_{2}\right)+(1-\theta) w_{2} k^{\prime} F_{L}^{3}\left(L_{1}+L_{2}\right)\right]\left[\alpha_{2}^{U} L_{1}\left(p_{1} q^{\prime} F_{L}^{1}-1\right)+\right.} \\
\left.\Omega_{2} w_{2}\left(1-\alpha_{2}^{T}\right)+\Omega_{2} \theta \bar{w} \alpha_{2}^{T}\right]-w_{2}\left(1-\alpha_{2}^{T} \theta\right) \Omega_{2}\left(\bar{w}-w_{2}\right) \\
{\left[1-(1-\theta) k^{\prime} F_{L}^{3}\left(L_{1}+L_{2}\right)\right]}
\end{array}\right\} / \Delta<0 \\
& \frac{d w_{3}}{d h}=-k^{\prime} F_{L}^{3}(1-\theta) w_{3}\left[\Omega_{0} \Omega_{2}\left(w_{2}-\bar{w}\right)-\Omega_{1} L_{2}-L_{2}\left(1-\alpha_{2}^{T}\right) w_{2} \Omega_{2}\right] \\
& -k F_{L L}^{3}\left\{\begin{array}{l}
-L_{2}\left[\alpha_{2}^{U} L_{1}\left(p_{1} q^{\prime} F_{L}^{1}-1\right)+w_{2} \Omega_{2}+\theta \alpha_{2}^{T} \Omega_{2}\left(\bar{w}-w_{2}\right)\right] \\
-\Omega_{2}\left(\bar{w}-w_{2}\right)\left[\Omega_{0}+(1-\theta) L_{2} \alpha_{2}^{T}\right]
\end{array}\right\}<0
\end{aligned}
$$

and

$$
\frac{d \beta}{d h}=-(1-\theta)\left[w_{3}-k F_{L L}^{3}\left(L_{1}+L_{2}\right)\right]\left[\Omega_{2} \Omega_{0}\left(w_{2}-\bar{w}\right)-\Omega_{1} L_{2}-w_{2}\left(1-\alpha_{2}^{T}\right) L_{2} \Omega_{2}\right] / \Delta<0
$$

From above results, we further obtain $d p_{2} / d h<0$ from equation (2). An increase in the per capita training cost will change the income and the consumption of migrants, which affect the proportion of remittances in migrants' income. In view of the results, we can establish the following results:

$$
\frac{d y_{T}}{d h}=\left(\begin{array}{l}
{\left[w_{3}-k F_{L L}^{3}\left(L_{1}+L_{2}\right)\right]\left[\Omega_{2} \bar{w} L_{2}\left(1-\alpha_{2}^{T}\right)+\Omega_{2}\left(\bar{w}-w_{2}\right) \bar{L}_{2}\left(1-\alpha_{2}^{U}\right)+\Omega_{1} L_{2}\right.} \\
\left.+(1-\theta) \Omega_{2} \bar{w} \Omega_{0}\left(\bar{w}-w_{2}\right)+(1-\theta) \Omega_{1} L_{2}+(1-\theta)\left(1-\alpha_{2}^{T}\right) w_{2} \Omega_{2} L_{2}\right]
\end{array}\right) / \Delta<0
$$

and

$$
\begin{aligned}
& \frac{d\left(\beta /\left(\bar{w} L_{1}+w_{2} L_{2}\right)\right)}{d h}= \\
& \frac{\left[k F_{L L}^{3}\left(L_{1}+L_{2}\right)-w_{3}\right]\left\{\begin{array}{l}
(1-\theta)\left(\bar{w} L_{1}+w_{2} L_{2}\right)\left[\Omega_{2} \Omega_{0}\left(w_{2}-\bar{w}\right)-\Omega_{1} L_{2}-\left(1-\alpha_{2}^{T}\right) w_{2} \Omega_{2} L_{2}\right]+ \\
\beta\left[\Omega_{2} \bar{w} L_{2}\left(1-\alpha_{2}^{T}\right)+\Omega_{2}\left(\bar{w}-w_{2}\right) \bar{L}_{2}\left(1-\alpha_{2}^{U}\right)+\Omega_{1} L_{2}\right]
\end{array}\right\}}{\Delta\left(\bar{w} L_{1}+w_{2} L_{2}\right)^{2}}<0
\end{aligned}
$$

From above results, we get

Proposition 1: In our assumed economy, an increase in the per capita training cost generates the following impacts: 
Internal Remittances, Vocational Training Costs and Rural-Urban Migration in Developing Countries

(1) A reduction in internal remittances and migrants' urban consumption;

(2) A decrease in the proportion of remittances in migrants' income.

An increase in the per capita training cost increases the cost of the manufacturing sector and reduces employment correspondingly. Reduced workforce flows into the informal sector, which also attracts agricultural employees. Therefore, an increase in the per capita training cost also promotes rural-urban migration. However, the more migrants work in the lowerwage informal sector while fewer migrants are employed in the high-wage manufacturing sector, brings down total migrants' income. Meanwhile, the expansion of the informal sector brings down its price and stimulates its consumption. Since the income of urban labor is constant, migrants' increase the consumption of informal goods at a lower price. A decreased total income and an increased informal consumption reduce the capacity of remittances, which lowers the proportion of remittances in migrants' income at last.

The change of employment and remittances also leads to the fluctuation of output. The informal sector expands with more employment while the agricultural sector experiences a loss with fewer remittances and workers. From the results of equation (8), we obtain

$$
\frac{d X_{2}}{d h}=F_{L}^{2} \frac{d L_{2}}{d h}>0
$$

and

$$
\frac{d X_{3}}{d h}=k^{\prime} F^{3} \frac{d \beta}{d h}+k F_{L}^{3} \frac{d L_{3}}{d h}<0
$$

We use Proposition 2 to summarize the impacts of an increase in per capita training cost on output in the informal and the agricultural sectors.

Proposition 2 An increase in per capita training cost contributes to an expanding informal sector and a contracting agricultural sector.

When the manufacturing sector faces structural adjustments and increases its training cost, rural-urban migrants experience unemployment in the manufacturing sector. Migrants who are in unemployment prefer to stay in the urban region, i.e., self-employment in the informal sector instead of returning to the agriculture. In this situation, the low-end informal sector expands. One theoretical explanation for this phenomenon is that migrants view informal sector employment as a temporary staging post for a way to gain formal sector employment (Johnson, 1971; Fields, 1975; Mazumdar, 1975). This hypothesis is supported by some economic reality (International Labour Office, 1972) and empirical research (Meng, 2001; Junankar and Shonchoy, 2013). This conclusion is also supported by China's economic facts. According to the National Monitoring Survey Report of Rural-Urban Migrant Workers from 2008 to 2016 in China, $37.2 \%$ and $33.8 \%$ of migrants employed in the manufacturing (excluding construction industry) and tertiary industry in 2008, respectively; however, when China faced industry upgrading and increased its training cost, the manufacturing sector dropped the employment of migrants while an increasing number of migrants employed in low-end tertiary rather than agricultural sector, and the figures were $30.2 \%$ and $46.7 \%$ in 2016 , 
respectively. At the same time, the number of migrants increased from the Survey Report. Ceteris paribus, the agricultural sector experiences a loss. In reality, the output of the agricultural sector may not fall because of the inflow of capital to substitute the transferred labor. Here, our model confines to the short term and does not consider the mobility of capital.

\section{Concluding remarks}

Based on the new phenomena of manufacturing in developing countries, the article analyzes theoretically impacts of an increase in per capita training cost on internal remittances. We find that an increase in per capita training cost in the manufacturing sector reduces internal remittances and the proportion of remittances in migrants' income. In addition, an increase in per capita training cost also contributes to expanding the informal sector and contracting the agricultural sector. Since similar analyses have been sparse, the main contents of this paper provide new perspectives to the best of our knowledge. Several important policy implications are derived from the findings in this study.

First, since the remittances have a positive impact on agricultural production, the government could put more financial resources into rural areas, such as provision of infrastructure, reduction of pollution, improvement of government service, to minimize negative impacts generated by a reduction of remittances. Second, reducing the per capita training cost would raise the employment of migrants and remittances in the urban area, and promote agricultural output and add agricultural wage in the rural area. Increment in the human capital level of the rural is an effective solution to drop the training cost. However, rural people could hardly afford the investment of human capital. The government should play a significant role, making policies to broaden access to basic education, strengthen the technical and vocational training programs, and improve school-industry partnerships, in effectively enhancing the human capital level of the rural. Third, many rural migrants will face unemployment when manufacturing increases its training cost and the informal sector provides jobs to them in the urban regions. Programs, such as provision of training, facilitation of micro-finance, reduction the cost of establishment and operation of a business (including simplified registration and licensing procedures, favorable tax conditions), legal protection, should be designed and implemented to promote the development of informal sector and ease the negative impacts resulted from an increase in training cost.

\section{References}

Adams, R.H. (2010), "Remittances, Household Expenditure and Investment in Guatemala", World Development, vol. 38, pp. 1626-1641.

Adams, R.H. (2013), "The Impact of Remittances on Investment and Poverty in Ghana", World Development, vol. 50, pp. 24-40.

Brauw, A. and Mueller, V. (2013), "Motives to Remit: Evidence from Tracked Internal Migrants in Ethiopia", World Development, vol. 50, pp. 13-23.

Cheng, E. and Xu, Z. (2005), "Domestic Money Transfer Services for Migrant Workers in China", See https://www.microfinancegateway.org/library/domestic-money-transfer-services-migrant-workerschina 
Internal Remittances, Vocational Training Costs and Rural-Urban Migration in Developing Countries

Djajic, S. (1985), "Human Capital, Minimum Wage and Unemployment: A Harris-Todaro Model of a Developed Open Economy”, Economica, vol. 52, pp. 491-508.

Fields, G.S. (1975), "Rural-urban migration, urban unemployment and underemployment, and job-search activity in LDCs", Journal of Development Economics, vol. 2, pp. 165-87.

Gupta, M.R. (1997), "Informal sector and informal capital market in a small open less-developed economy", Journal of Development Economics, vol. 52, pp. 409-428.

International Labour Office (1972), "Employment, Incomes and Equality: A Strategy for Increasing Productive Employment in Kenya", Geneva.

Li, X. and Wang, D. (2015), “The impacts of rural-urban migrants' remittances on the urban economy”, The Annals of Regional Science, vol. 54, pp. 591-603.

Li, X. and Zhou, J. (2015), "Environmental effects of remittances of rural-urban migrant”, Economic Modelling, vol. 47, pp.174-179.

Li, X. and Zhou, Y. (2013a), "An Economic Analysis of remittances of Unskilled Migration on SkilledUnskilled Wage Inequality in Labor Host Region”, Economic Modelling, vol. 33, pp. 428-432.

Li, X. and Zhou, Y. (2013b), "Economic and Environmental Effects of Rural-Urban Migrant Training", Prague Economic Papers, vol. 3, pp. 385-402.

Johnson, G. (1971), “The structure of rural-urban migration models", East Africa Economic Review, vol. 3, pp. 21-28.

Junankar, P.N. and Shonchoy, A. (2013), “The Informal Labour Market in India: Transitory or Permanent Employment for Migrants?”, Discussion Paper No. 7587. The Institute for the Study of Labour (IZA), Bonn.

Kar, S. and Marjit, S. (2001), "Informal sector in general equilibrium: welfare effects of trade policy reforms", International Review of Economics \& Finance, vol. 10, pp. 289-300.

Knight, J., Song, L. and Jia, H. (1999), "Chinese rural migrants in urban enterprises: Three perspectives", Journal of Development Studies, vol. 35, pp. 73-104.

Niimi, Y., Pham, T.H. and Reilly, B. (2009), "Determinants of Remittances: Recent Evidence Using Data on Internal Migrants in Vietnam", Asian Economic Journal, vol. 23, pp. 19-39.

Mazumdar, D. (1975), "The theory of urban underemployment in less developed countries", World Bank Staff Working Paper, No. 198.

Meng, X. (2001), "The Informal Sector and Rural-Urban Migration-A Chinese Case Study", Asian Economic Journal, vol. 15, pp. 71-89.

Meng, X. and Zhang, J. (2001), "The Two-Tier Labor Market in Urban China: Occupational Segregation and Wage Differentials between Urban Residents and Rural Migrants in Shanghai", Journal of Comparative Economics, vol. 29, pp. 485-504.

Muller, V. and Shariff, A. (2011), "Preliminary evidence on internal migration, remittances, and teen schooling in India", Contemporary Economic Policy, vol. 29, pp. 207-217.

Samanta, S. (2003), “Training, Unemployment and Fiscal Subsidy: A Harris-Todaro Approach”, SSRN Working Paper Series, See http://ssrn.com/abstract=471981.

Tumbe, C. (2011), "Remittances in India: Facts and Issues", Indian Journal of Labour Economics, vol. 54, pp. 479-501.

World Bank (2016), "Migration and Remittances Factbook 2016". 